\title{
A responsabilidade das organizações diante do impacto social de sua comunicação no ambiente virtual
}

The responsibility of the organizations due to the social impact of their communication in the virtual environment

La responsabilidad de las organizaciones delante del impacto social de su comunicación en el ambiente virtual

\section{Mariana Carareto}

- Mestranda no Programa de Pós-Graduação em Comunicação Midiática da Universidade Estadual Paulista (Unesp) - Bauru

- Especialista em Gestão Estratégica em Comunicação Organizacional e Relações Públicas pela Escola de Comunicações e Artes da Universidade de São Paulo (ECA-USP)

- Bacharel em Relações Públicas pela Unesp - Bauru

- E-mail: marianacarareto@gmail.com

\section{Renata Calonego}

- Mestranda no Programa de Pós-Graduação em Comunicação Midiática da Universidade Estadual Paulista (Unesp) - Bauru

- Bacharel em Relações Públicas pela Unesp - Bauru

- Membro do Grupo de Pesquisa "Relações públicas e comunicação: opinião pública, educação e interculturalidade" e da rede aberta de pesquisa "Collaborative open learning" (Colearn)

- E-mail:rcalonego@gmail.com

\section{Roseane Andrelo}

- Doutora em Educação Escolar pela Unesp - Araraquara, com bolsa-sanduíche da Capes para pesquisa na Université Paris III

- Docente do Programa de Pós-Graduação em Comunicação Midiática e do Curso de Relações Públicas da Unesp - Bauru

- Mestre em Comunicação Midiática e bacharel em Jornalismo pela Unesp - Bauru

- E-mail: roseane.andrelo@faac.unesp.br 


\section{Resumo}

0 artigo apresenta uma reflexão sobre a responsabilidade das organizações ao disseminarem seus discursos nas mídias sociais. 0 objetivo é demonstrar como a comunicação organizacional, diante de seu impacto social, pode dialogar sobre questões éticas que estimulem respeito na sociedade a partir das relações estabelecidas em comunidades virtuais. Para isso, foi desenvolvida uma análise de conteúdo das interações dos públicos nas campanhas da Skol e da Alezzia no Facebook.

PALAVRAS CHAVE: MÍDIAS SOCIAIS • COMUNIDADES VIRTUAIS • COMUNICAÇÃO ORGANIZACIONAL・RESPONSABILIDADE SOCIAL.

\section{Abstract}

The article presents an analysis about the responsibility of organizations when disseminating their speeches in social media. The purpose is to demonstrate how organizational communication, in view of its social impact, can dialogue on ethical topics that stimulate respect in society, based on relationships established in virtual communities. Focused on that, a content analysis was developed, considering the interactions of the audiences in Skol and Alezzia campaigns on Facebook.

KEYWORDS: SOCIAL MEDIA •VIRTUAL COMMUNITIES・ORGANIZATIONAL COMMUNICATION • SOCIAL RESPONSIBILITY.

\section{Resumen}

El artículo reflexiona acerca de la responsabilidad de las organizaciones cuando diseminan sus discursos en las redes sociales online. El objetivo es demostrar cómo la comunicación organizacional, delante de su impacto social, puede dialogar sobre cuestiones éticas que estimulan respeto en la sociedad a partir de las relaciones establecidas en comunidades virtuales. Así, fue desarrollado un análisis de contenido de las interacciones de los públicos en las campañas de Skol y Alezzia en Facebook. 
stransformações ocasionadas pelo desenvolvimento tecnológico refletiram nas diversas esferas da sociedade, incluindo
as organizações, que vivenciam alterações na dinâmica de suas relações. As possibilidades de acesso à informação e
interação resultaram na aproximação com seus públicos, deixando seu comportamento mais exposto, aumentando as cobranças em relação aos impactos de sua atividade e, consequentemente, a necessidade de assumir responsabilidades e dialogar com a sociedade. Esse processo, também marcado pelas mudanças econômicas, políticas e sociais, criou condições para o crescimento de pressões cidadãs, as quais afetam o funcionamento das organizações (Srour, 2013).

Origina-se uma interdependência das organizações com a sociedade, sendo exigida uma relação de comprometimento, ética (Ferrari, 2011) e respostas. Nesse contexto, a comunicação organizacional se torna responsável por viabilizar e consolidar ações que promovam relacionamento para disseminar princípios e valores, estabelecer diálogo com os públicos para atender aos questionamentos e criar estratégias e condições que garantam o equilíbrio entre os interesses sociais e organizacionais.

Cabe, diante disso, compreender o impacto social que a comunicação pode gerar ao estabelecer uma relação ética, ou seja, que atenda, com respeito, os problemas gerais da sociedade e, consequentemente, seja socialmente responsável (Srour, 2013). Com esse raciocínio, é possível refletir, por exemplo, sobre seu papel como educadora ao debater e desconstruir valores destrutivos, como preconceitos sociais, raciais, culturais e sexuais.

Logo, a comunicação das organizações, se praticada nessa lógica, pode ser um importante agente de transformação social, uma vez que influencia, em certa medida, o comportamento da sociedade e a opinião pública. 0 ambiente virtual e as comunidades constituídas mediante a presença on-line das organizações potencializam ainda mais esse processo, colocando o interesse coletivo em pauta.

Nessa perspectiva, este trabalho tem por objetivo verificar se a comunicação organizacional se tornou um meio para dialogar sobre questões éticas que estimulem respeito na sociedade a partir das relações estabelecidas em comunidades virtuais. Para isso, foi realizada uma fundamentação teórica que busca demonstrar como a sociedade conectada e participativa e, consequentemente, as comunidades virtuais constituídas estimulam a relação de responsabilidade das organizações para a construção de valores éticos. Posteriormente, desenvolveu-se uma análise de conteúdo das reações causadas nos públicos pelo discurso de duas campanhas com posicionamentos distintos: da Skol e da Alezzia.

\section{A RESPONSABILIDADE DAS ORGANIZAÇÕES E O PAPEL DA COMUNICAÇÃO ORGANIZACIONAL DIANTE DAS POSSIBILIDADES DE PARTICIPAÇÃO DO AMBIENTE VIRTUAL}

Com o desenvolvimento das tecnologias de informação e comunicação, diversas dinâmicas e estruturas sociais se alteram, interferindo diretamente nos formatos e nas estratégias de relacionamento das organizações (Srour, 2012). 0 principal fator foi o advento da internet, que possibilitou e potencializou os intercâmbios de informação; a interação entre os indivíduos, independentemente da distância; o consumo de produtos e serviços do mundo todo; a formação de comunidades em torno de interesses específicos para serem debatidos e disseminados; o engajamento e a mobilização dos indivíduos em assuntos de cunho político, social, cultural. 
Segundo Recuero (2010), a expansão da internet ampliou a capacidade de conexão entre as pessoas e marcou o surgimento da sociedade conectada, o que facilitou a criação de redes sociais virtuais, as quais possuem "um alto grau de interatividade, colaboração e produção/uso/consumo de conteúdos" (Martino, 2015, p. 13). Com o desenvolvimento de plataformas on-line, como as mídias sociais, é estabelecida uma cultura de interação, de consumo e de participação, alterando o funcionamento da sociedade, tanto para os indivíduos, quanto para as organizações.

Diante disso, o ambiente on-line admite oportunidades de compartilhamento de conteúdos e ideias que refletem desde decisões sobre o consumo de algum produto, até as mobilizações para cobranças e garantia de direitos. À medida que se fortalecem a discussão e participação em assuntos de interesse público e as possibilidades de expor e disseminar opiniões, a internet se configura, mesmo que de maneira incipiente, em um instrumento para ações coletivas e mobilizações sociais, culturais e políticas, o que exige das organizações maior diálogo para construir relacionamentos. Assim, pode-se afirmar que a internet se tornou um espaço para potencializar "ações de caráter político-social" por meio da disseminação de informações e promoção da discussão coletiva na rede (Luvizotto; Seridório, 2016, p. 208), principalmente quando os interesses comuns dos sujeitos se encontram e, em busca de mudanças, se unem no ambiente on-line.

Nesse sentido, as relações entre as diversas partes da sociedade adquirem uma perspectiva semelhanteà de uma comunidade, porém no ambiente virtual. As comunidades virtuais referem-se, segundo Rheingold (1996, p. 20), aos agrupamentos sociais formados na rede on-line "quando uma quantidade suficiente de gente leva adiante essas discussões públicas durante um tempo suficiente, com suficientes sentimentos humanos, para formar redes de relações pessoais no espaço cibernético".

As características de uma comunidade virtual podem ser identificadas tanto nos espaços off-line quanto nos on-line, pois 0 contato estabelecido através da internet pode levar adiante uma discussão e criar o sentimento de pertencimento. A partir dessas relações sociais construídas no ambiente virtual, portanto, podem surtir reflexos, em grande ou pequena medida, na vida off-line das pessoas (Recuero, 2001).

Logo, o ambiente virtual, diante da possibilidade de construção de comunidades virtuais, viabiliza um espaço mais participativo e democrático, uma vez que a associação dos atributos de uma comunidade unidos ao acesso às informações, à liberdade de expressão e até mesmo às garantias do exercício da cidadania são práticas existentes. Luvizotto e Seridório (2016) afirmam que é possível verificar que os indivíduos da nova geração já utilizam a internet para se aproximarem de causas com as quais se identificam e como um meio para exercer seus direitos a partir do diálogo e das possibilidades de debate.

No geral, os reflexos da modificação das formas de comunicação e consumo de informação atingem a configuração da sociedade como um todo, uma vez que, de acordo com Luvizotto e Seridório (2016), o espaço virtual possibilitou a manifestação de demandas e interesses dos sujeitos e grupos sociais. Essa configuração traz desafios para as organizações, que passam a enfrentar pressões devido à maior exposição de sua ação e à aproximação com seus públicos.

A estruturação dessa sociedade pautada no ambiente digital e participativo acarreta um cenário complexo para as organizações, tanto públicas quanto privadas, pois a criticidade do público antes de consumir um produto ou serviço é potencializada, influenciando a performance organizacional. Com isso, conforme enfatizam Jenkins, Green e Ford (2014), as organizações são pressionadas a estabelecer canais de diálogo com seus públicos, seja para ouvir ou responder seus interesses.

As mídias sociais, portanto, criam condições para que esses canais sejam estabelecidos e, ao mesmo tempo, ampliam as cobranças de responsabilidades das organizações em relação aos impactos causados e à garantia de bem-estar aos 
indivíduos, ou seja, cobranças por atitudes socialmente responsáveis. É nesse contexto que o retorno econômico se torna insuficiente para o sucesso das organizações e o retorno social se fortalece, pois as transformações ocorridas fazem com que elas necessitem de uma "licença social para operar" (Srour, 2013, p.178).

A licença social é conquistada por meio de atitudes éticas, ou seja, atitudes que orientem as organizações por princípios e valores capazes de assumir as responsabilidades por impactos causados na sociedade. Diante disso, um dos fatores relacionado à ética organizacional são as políticas e ações de responsabilidade social, a qual remete, de acordo com Srour (2012, p. 58), "à intervenção virtuosa das empresas na melhoria da qualidade de vida de seus públicos de interesse". Dessa forma, a responsabilidade das organizações

\begin{abstract}
implica parceria efetiva com clientes e fornecedores, gerando produtos de qualidade e assegurando durabilidade, confiabilidade e preços competitivos; Supõe contribuições para o desenvolvimento da comunidade, via projetos que aumentem o bem-estar; Provoca investimentos em pesquisa tecnológica para inovar processos e produtos para melhor satisfazer clientes ou usuários; Exige respeito ao meio ambiente e neutralização da pegada ecológica através de intervenções não predatórias (consciência da vulnerabilidade das condições de habitabilidade do planeta) e por meio de medidas que certifiquem a origem dos insumos, utilizem energias renováveis e evitem externalidades negativas; Requer capacitação profissional dos trabalhadores e participação deles em decisões técnicas, assim como requer inversões em segurança do trabalho, em melhores condições de trabalho e em benefícios sociais; Prescreve a não discriminação e o tratamento equânime dos trabalhadores, além de procurar beneficiar os demais públicos de interesse (Srour, 2012, p. 58).
\end{abstract}

Além dos fatores que envolvem as responsabilidades sociais, as organizações devem se pautar por princípios básicos que orientem suas políticas, estratégias e atividades. São eles: accountability (prestação de contas e responsabilização por seus atos); transparência (comunicar sobre suas decisões e atividades); comportamento ético; respeito aos interesses das partes interessadas (respeitar, considerar e responder aos interesses das partes); respeito pelo Estado de direito (respeitar a lei); respeito às normas internacionais de comportamento; e respeito pelos direitos humanos (Smith, 2013).

Segundo Srour (2013), reflexões éticas são essenciais na tomada de decisões e, para isso, é preciso a adoção de uma postura socialmente responsável, com ações pautadas tanto para os interesses organizacionais, quanto para os coletivos. Nesse sentido, acredita-se que a comunicação organizacional exerça um importante papel para garantir que interesses coletivos e organizacionais estejam em constante diálogo e interação, possibilitando que as organizações tenham conhecimento e condições para atuarem de forma ética.

Conforme apontam Oliveira e Paula (2010), considerando que os grupos sociais são impactados pela ação das organizações e conseguem se mobilizar para defender seus interesses, elas precisam reconhecer as consequências de sua atividade para alcançar seus objetivos. A comunicação é uma forma para estabelecer a relação entre as organizações e esses grupos, pois é por meio dos discursos que elas se apresentam "como atores que participam e buscam se comprometer com o desenvolvimento da sociedade, para garantir, em última instância, sua sustentação e credibilidade junto à sociedade" (Oliveira; Paula, 2010, p. 40). As autoras ressaltam ainda que essa relação vai além do paradigma informacional da comunicação, pois, os discursos das organizações passaram a ser confrontados, respondidos pelos diversos grupos sociais a partir de suas expectativas e interesses, o que influencia no modo organizacional de comunicar e agir.

Considerando esse cenário e as potencialidades de participação da sociedade conectada, verifica-se que os confrontamentos direcionam a comunicação das organizações para uma perspectiva relacional, a qual "implica no reconhecimento da diversidade de percepções, posições e divergências dos atores da interação, que se manifestam no ambiente organizacional muitas vezes como crítica, resistência, rejeição e silêncio" (Oliveira; Paula, 2010, p. 42). De acordo 
com as autoras, essa perspectiva favorece a reflexão dos posicionamentos, as mudanças de comportamento e a tomada de decisões tanto das organizações quanto dos indivíduos.

A comunicação, nesse cenário, assume uma posição fundamental para fortalecer ações responsáveis e viabilizar o diálogo e o relacionamento com a sociedade, dando consistência ao compromisso social. Ressalta-se, no entanto, conforme aponta Henriques (2009), que é essencial que essa comunicação tenha como base um horizonte ético para que seja possível a transformação da realidade e, assim, se tornar articulada para a representatividade, alinhando-se com as características de uma gestão socialmente responsável. Para isso, é preciso utilizar meios que potencializem o diálogo diante dos questionamentos e sentidos construídos pelos discursos organizacionais e, por isso, a presença on-line das organizações torna-se imprescindível por ser um ambiente que, segundo Jenkins, Green e Ford (2014), permite a interação constante e a construção de relacionamentos.

As organizações, portanto, configuram-se como importantes agentes de sensibilização da sociedade e da opinião pública sobre diversos temas, podendo potencializar transformações sociais e influenciar interesses coletivos, principalmente quando estão presentes no espaço on-line e formam comunidades virtuais em seu entorno.

Nesse sentido, o presente trabalho busca ampliar o conceito de comunicação pública e de comunicação comunitária para além de espaços limitados à ideia de segundo ou terceiro setor. Para tanto, baseia-se na concepção de Matos (2009), que, ao se referir à comunicação pública, propõe um olhar mais amplo do que a comunicação realizada no âmbito de poderes instituídos e alerta: "o foco dos estudos tem deixado de lado a interação comunicativa nas e entre as redes sociais" (Matos, 2009, p. 27).

É importante compreender que a atuação das organizações gera questões de interesse público e o papel da comunicação é ativar, por meio das redes sociais, diálogos que viabilizem um debate para ação coletiva. Diante disso, conforme Matos (2009), há uma tendência de deslocamento conceitual da responsabilidade social das organizações para a formação do capital social, por ser o componente para "articular as experiências concretas dos sujeitos contemporâneos em redes de engajamento cívico, nas quais são estabelecidas normas de reciprocidade e confiança generalizada" (Matos, 2009, p. 19), e, assim, viabilizar a ação coletiva e comprometimento social das organizações.

Na perspectiva adotada por Matos (2009), a conversação, como uma forma de interação existente nas trocas comunicativas cotidianas, mesmo que na modalidade virtual, é resgatada e privilegiada.

A especificidade da conversação estaria, assim, na pretensa capacidade que ela possui de abrir caminho para a emergência de opiniões conflitantes (anteriormente latentes) e na capacidade dos interlocutores para partir de temas fluidos e dispersos e avançar rumo a um diálogo mais focado em assuntos ou problemas de interesse coletivo, voltando suas interações para 0 entendimento (Matos, 2009, p. 71).

Diante disso, é possível inserir na discussão o papel das organizações, inclusive as privadas, como mediadoras dessa interação e, por conseguinte, como construtoras do capital social, o que complementa e concretiza as responsabilidades das organizações na sociedade orientadas por um processo participativo. Partindo dessa ideia e considerando a potencialização do espaço on-linee a formação de comunidades virtuais, amplia-se a discussão acerca das responsabilidades da comunicação das organizações para a construção de valores éticos que reflitam positivamente nas relações sociais. Para isso, foi desenvolvido um estudo de campanhas com posicionamentos distintos para verificar as reações geradas no ambiente virtual e, assim, discutir as responsabilidades da comunicação organizacional. 


\section{A RESPONSABILIDADE DA COMUNICAÇÃO NA SOCIEDADE CONECTADA: ANALISANDO AS CAMPANHAS DA SKOL E DA ALEZZIA}

Diante da discussão apresentada, foi realizado um estudo para demonstrar como a comunicação organizacional, considerando a ação socialmente responsável das organizações, se tornou um meio para dialogar sobre questões éticas que reflitam no respeito entre os indivíduos. Para isso, desenvolveu-se uma análise de conteúdo da campanha de verão da Skol e da campanha realizada pela empresa de móveis Alezzia, pois ambas ocorreram no ambiente virtual (Facebook) e trataram de questões de gênero, porém com abordagens opostas, as quais geraram debates que refletem, na perspectiva da teoria apresentada, na construção de relações éticas.

As duas campanhas tiveram início em dezembro de 2016, contando com mais de uma postagem. A Skol desenvolveu, além de peças para a campanha, um vídeo publicitário, postado duas vezes; já a campanha da Alezzia foi composta por postagens que abordaram diversas vezes o discurso da empresa. Para escolher as postagens analisadas utilizou-se como critério o número de interações, ou seja, o número de comentários nas duas campanhas deveria ser semelhante e, além disso, o discurso disseminado deveria explicitar o propósito da campanha.

Para a Skol, foi escolhida a segunda postagem do vídeo publicitário, o qual apresentava um posicionamento para enaltecer as diferenças e o respeito entre as pessoas, estimulando reflexões sobre a importância da diversidade e a quebra dos padrões estéticos. 0 discurso do vídeo acompanhava um texto dividido em duas partes, como pode ser verificado na Figura 1.

Figura 1-Campanha da Skol'.

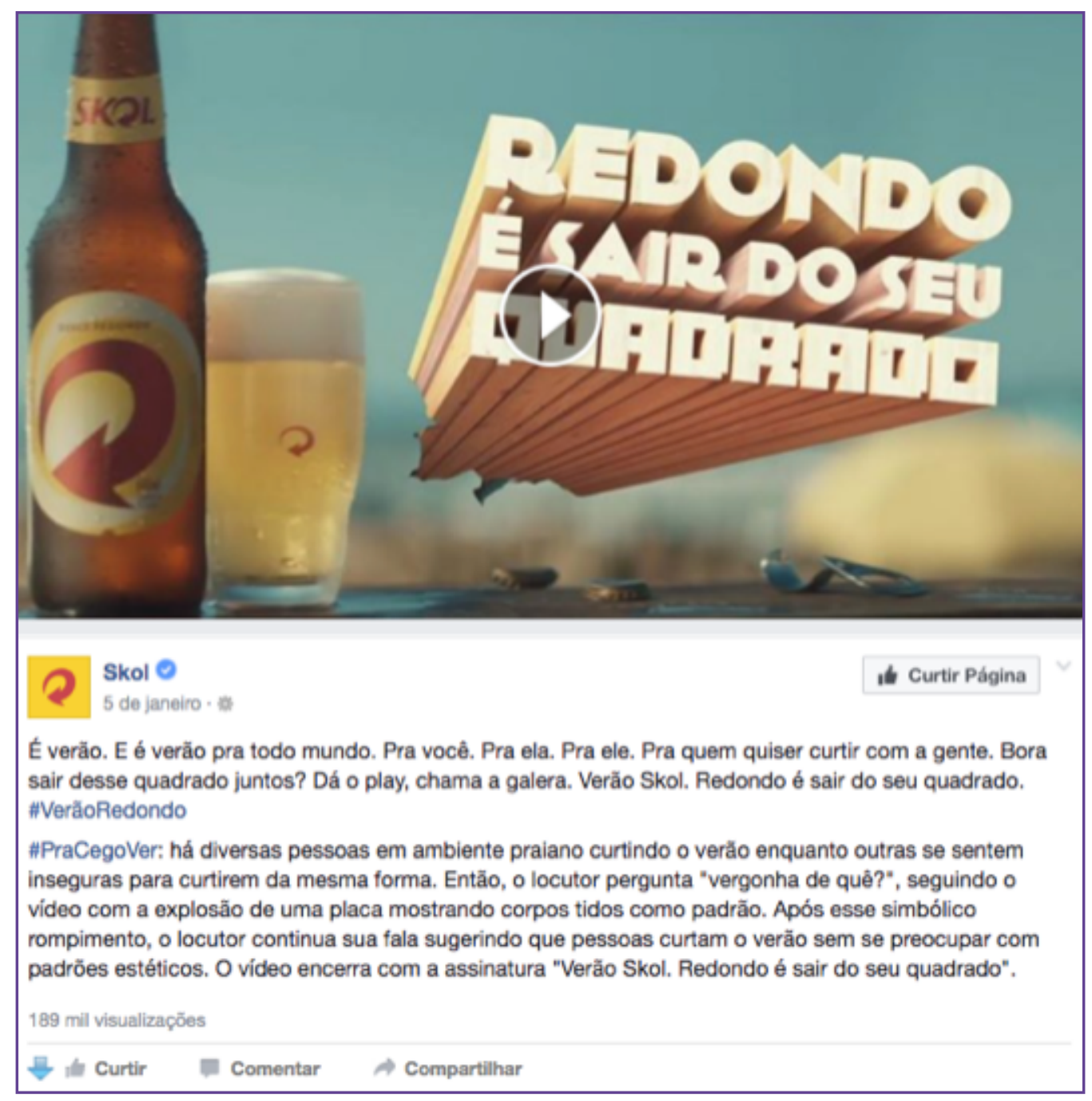

1 Disponível em: <www.facebook.com/skol/videos/10154980059947958>. Acesso em: 10 fev. 2017. 
0 texto é composto, primeiramente, por uma chamada para assistir à propaganda com indicações sobre o conceito que está sendo disseminado. A segunda parte, iniciada com a \#PraCegoVer, é uma descrição do conteúdo do vídeo para possibilitar acessibilidade e inclusão nas redes sociais. É explícita a intenção da campanha em romper preconceitos construídos na sociedade, reforçando, com a expressão "Redondo é sair do seu quadrado", a importância de as pessoas mudarem alguns comportamentos.

A campanha da Alezzia tem um objetivo diferente: foi lançada como um desafio após a repercussão do posicionamento polêmico do proprietário em um grupo de designers. Ao insinuar que os homens são melhores designers do que as mulheres, ele foi criticado por integrantes do grupo, que acusaram de machista a postagem realizada, assim como as publicidades da empresa, muitas com a exposição do corpo feminino. Uma integrante expôs a situação e sua opinião no Facebook por meio de um relato, avaliando a Alezzia negativamente. A repercussão gerou uma série de críticas e avaliações negativas para a empresa, que além de respondê-las reforçando o posicionamento do proprietário, lançou o Desafio Alezzia (Figura 2):

Figura 2 - Campanha da Alezzia².

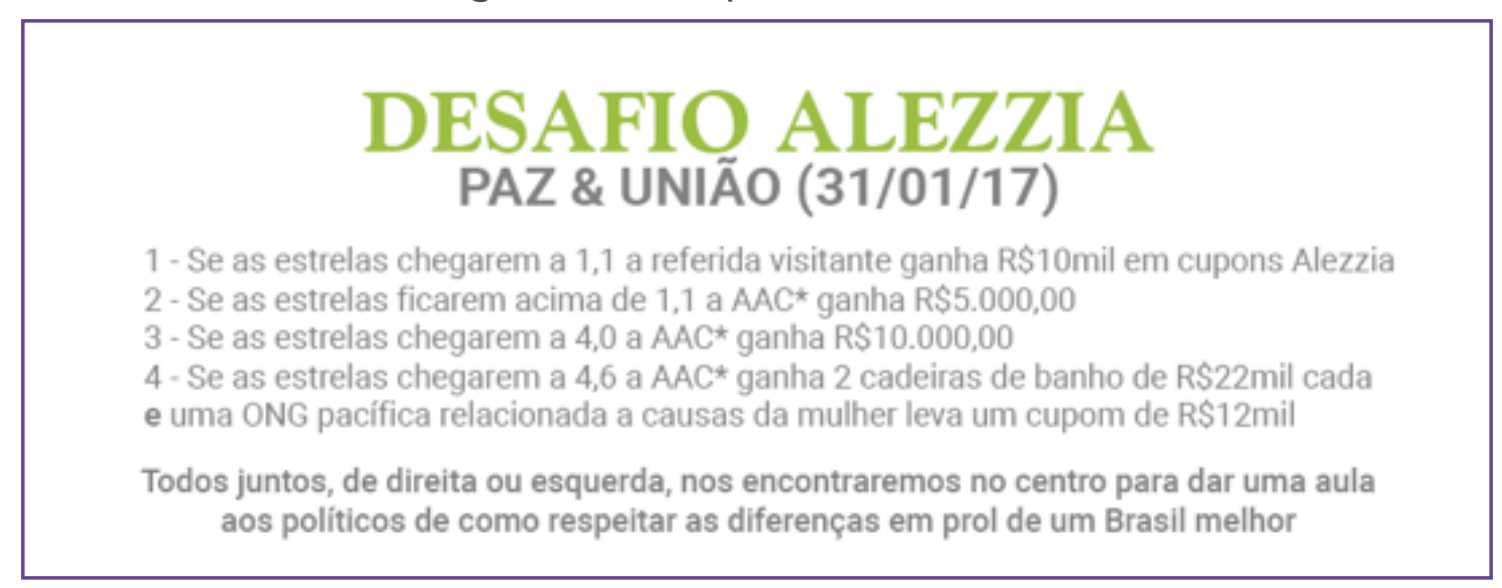

Inicialmente, a polêmica girou em torno do debate feminista. Por um lado, acusações de desrespeito com a mulher e, por outro, apoiadores da empresa que não concordam com o posicionamento adotado. A repercussão crescente fez com que a Alezzia unisse a essa discussão a importância da liberdade de expressão, expondo que as organizações devem afirmar suas reais opiniões e não construir um discurso politicamente correto por pressões (Figura 3).

Figura 3 - Postagem da Alezzia³.

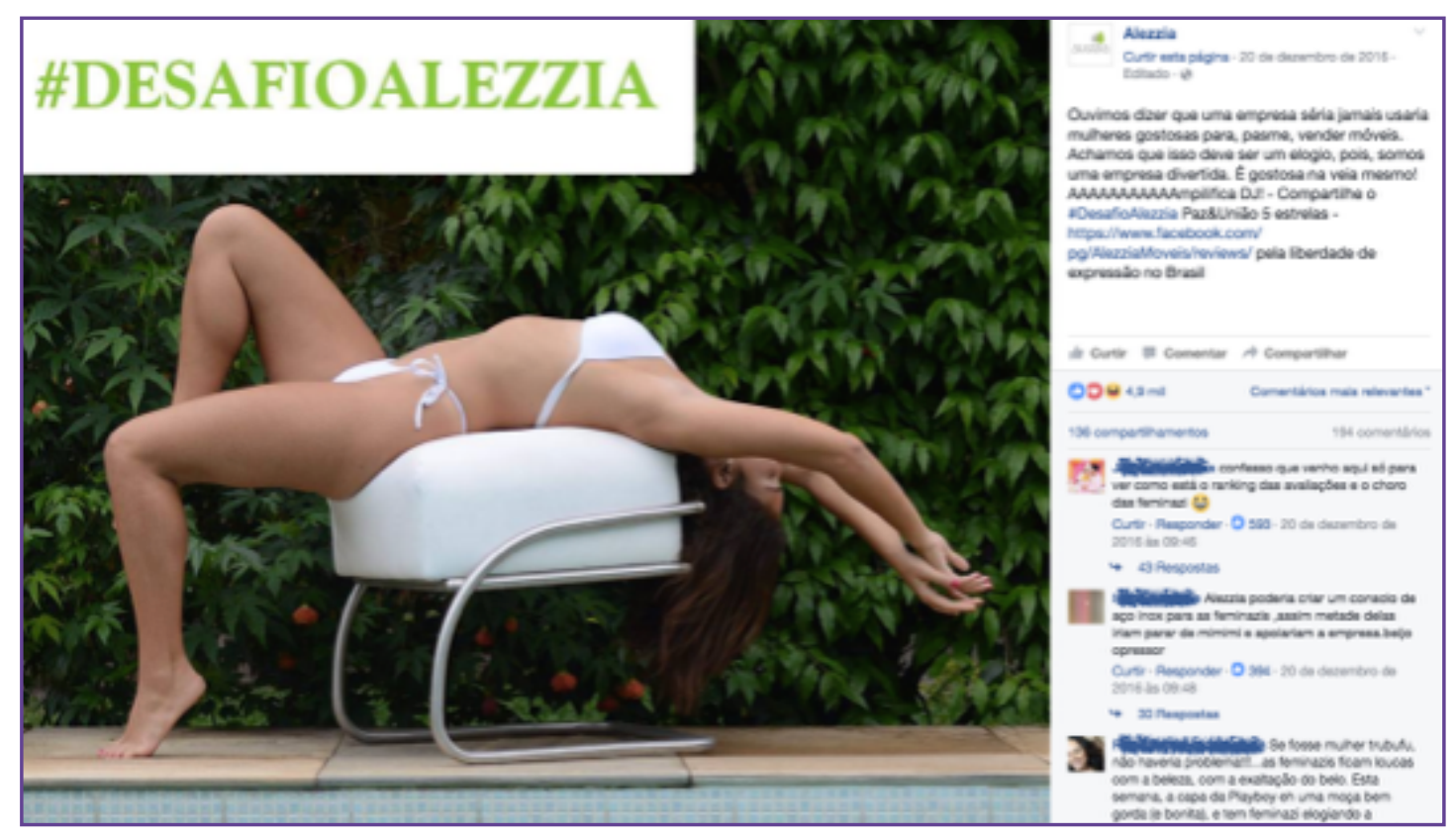

2 Disponível em: <www.facebook.com/AlezziaMoveis/photos/a.324681324261641. 85226.225545557508552/1438642832865479/?type=3\&theater>. Acesso em: 10 fev. 2017. 3 Disponível em: <www.facebook.com/AlezziaMoveis/photos/a.247407785322329. 70402.225545557508552/1441039009292528/?type=3\&theater>. Acesso em: 10 fev. 2017. 
No geral, a campanha da Skol gerou repercussão positiva por abordar a diversidade entre as pessoas, quebrando padrões estéticos, e por ser uma propaganda de cerveja com um novo conceito: debate sobre liberdade e igualdade sem objetificar o corpo da mulher como as marcas de cerveja sempre fizeram. Por outro lado, a Alezzia gerou repercussão polêmica, pois a organização assumiu um discurso que enfrenta os debates atuais sobre diversidade de gênero, justificando sua posição com a importância da liberdade de expressão.

Com as duas campanhas, verifica-se que os posicionamentos e as intenções dos discursos são opostos, sendo importante refletir sobre os sentidos que eles constroem nos sujeitos que interagem no ambiente virtual. Compreende-se que a comunicação organizacional estimula valores construtivos e destrutivos para a sociedade, porque, enquanto uma campanha fala sobre a importância da igualdade, a outra desconstrói esse significado, reforçando estereótipos.

Portanto, para o alcance do objetivo deste estudo foram analisados os sentidos construídos pelos discursos, verificando os comentários realizados na postagem de cada campanha. Foi desenvolvida uma análise quantitativa e qualitativa para possibilitar a reflexão sobre a responsabilidade da comunicação organizacional no estímulo de comportamentos éticos a partir das reações geradas: identificação; reações violentas; tensões e conflitos; discussão ética ou não.

Como metodologia, foi desenvolvida uma análise de conteúdo por ela possibilitar o desmembramento das mensagens textuais e, assim, a verificação dos sentidos construídos pelos discursos. Para isso, os comentários foram categorizados para a "classificação e reagrupamento (...) em número reduzido (...), com o objetivo de tornar inteligível a massa de dados e sua diversidade" (Fonseca Júnior, 2006, p. 298). Inicialmente, foram coletados os números de alcance das publicações e, posteriormente, os comentários delas foram agrupados e analisados em categorias que expressam os atributos que as campanhas reforçaram para os públicos.

0 vídeo da Skol teve 189 mil visualizações e 436 compartilhamentos, tendo as reações sido: 3.800 pessoas curtiram, 172 amaram, 41 acharam engraçado, 15 se surpreenderam, 2 consideraram triste e 2 não curtiram. Foram analisados todos os comentários, um total de 145, tendo 6 deles sido com diálogos entre as pessoas, que, no geral, geraram reações positivas e reforço de atributos construtivos, tanto para a marca, quanto para a sociedade. No Quadro 1 encontram-se os atributos reforçados:

Quadro 1- Campanha da Skol: atributos para o público.

\begin{tabular}{|l|c|}
\hline \multicolumn{1}{|c|}{ Atributos reforçados } & № de citações \\
\hline Elogios para a campanha & 45 \\
\hline Apreciação pela cerveja & 20 \\
\hline Emoticons positivos para a campanha & 15 \\
\hline Campanha que quebra estereótipos e padrões estéticos & 7 \\
\hline Pessoas que se sentiram representadas & 7 \\
\hline Brincadeiras sobre a bebida & 7 \\
\hline Alertas sobre o consumo de bebidas alcóolicas & 6 \\
\hline
\end{tabular}


ANO 14 • NÚMERO 26 • 1으․ 2017 • ORGANICOM

A RESPONSABILIDADE DAS ORGANIZAÇÕES DIANTE DO IMPACTO SOCIAL DE SUA COMUNICAÇÃ̃O NO AMBIENTE VIRTUAL

\begin{tabular}{|l|c|}
\hline \multicolumn{1}{|c|}{ Atributos reforçados } & № de citações \\
\hline Crítica à qualidade da Skol & 5 \\
\hline Diálogo amigável & 5 \\
\hline Propaganda que não objetificar o corpo da mulher & 3 \\
\hline Propaganda que respeita a diversidade & 2 \\
\hline Críticas negativas para a campanha & 2 \\
\hline Emoticons negativos para a campanha & 1 \\
\hline Diálogo conflituoso & 1 \\
\hline
\end{tabular}

Fonte: Elaborado pelas autoras.

Verifica-se que as características da maioria dos atributos reforçados na campanha da Skol fazem elogios ao posicionamento por meio de textos e de emoticons. Esses elogios referiam-se, em muitos casos, ao fato de o vídeo quebrar os estereótipos impostos por padrões estéticos na sociedade, por não objetificar ou enaltecer o corpo da mulher e por respeitar a diversidade que existe entre as pessoas. Além disso, o posicionamento exposto pela Skol gerou identificação em algumas pessoas, que afirmaram se sentirem representadas; os diálogos que ocorreram na postagem foram amigáveis, ou seja, enalteciam ser bom uma organização quebrar os preconceitos e ampliar o debate sobre a diversidade. 0 único momento de conflito se deu em uma crítica feita sobre a campanha.

Esses são fatores diretamente relacionados ao tema abordado pela campanha, mas atributos sobre a cerveja e seu consumo também foram registrados. No geral, alguns comentários fizeram brincadeiras sobre o consumo da cerveja, como, por exemplo, a frase "Se dirigir, não beba e, se beber, me convida", citada por uma pessoa; sobre a qualidade da Skol; e sobre os problemas de ingerir bebidas alcoólicas, enaltecendo riscos do consumo excessivo do álcool e a importância do fim da publicidade de bebidas alcóolicas.

Apesar de algumas críticas e associações negativas, é possível afirmar que a repercussão da campanha gerou sentidos positivos para a construção das relações sociais, ou seja, o discurso colabora para incentivar respeito entre os sujeitos. Isso ocorre, pois as características dos sentidos construídos pela Skol, no geral, estão associadas à importância do respeito e da igualdade de gênero.

A postagem da Alezzia teve 137 compartilhamentos e as reações foram: 4.000 pessoas curtiram, 435 amaram, 341 acharam engraçado, 57 não curtiram, 8 pessoas ficaram surpreendidas e 5 consideraram a publicação triste. No total foram analisados os 194 comentários, tendo 22 deles sido com diálogos entre as pessoas. Pelo fato de a campanha ter gerado polêmica, os comentários feitos na postagem tiveram reações diferentes dos comentários da campanha da Skol. No agrupamento dos atributos reforçados pelo público foi possível verificar que houve mais violência e embates nos diálogos e nas interações, tendo sido utilizadas muitas expressões agressivas e sarcásticas, grande parte apoiando 0 discurso da organização, como pode ser observado no Quadro 2: 
Quadro 2 - Campanha da Alezzia: atributos para o público.

\begin{tabular}{|c|c|}
\hline Atributos reforçados & № de citações \\
\hline Apoio para a empresa e campanha & 47 \\
\hline Comentários negativos sobre o Movimento Feminista & 43 \\
\hline Culto ao corpo feminino & 35 \\
\hline Comentários sarcásticos & 28 \\
\hline Comentários agressivos & 26 \\
\hline Reforço de estereótipos sobre feministas & 25 \\
\hline Acusação de desrespeito com a mulher & 15 \\
\hline Marketing negativo para a empresa & 15 \\
\hline Crítica à campanha "Desafio Alezzia" & 13 \\
\hline Diálogos conflituosos & 12 \\
\hline Comentários sobre política & 9 \\
\hline Comentários preconceituosos & 8 \\
\hline Emoticons negativos para a campanha & 6 \\
\hline Reforço de padrões estéticos & 4 \\
\hline Emoticons positivos para a campanha & 4 \\
\hline Marketing positivo para a empresa & 3 \\
\hline Elogio para os móveis da empresa & 2 \\
\hline Crítica para os móveis da empresa & 2 \\
\hline
\end{tabular}

Fonte: Elaborado pelas autoras.

Os atributos reforçados pelo público que interagiu na publicação trazem diversas características que retratam os sentidos construídos pelo discurso da empresa. São elas:

- Comentários negativos sobre o Movimento Feminista: referem-se à falta de moral e coerência das atitudes feministas. 0 movimento foi considerado intolerante, hipócrita e radical, o qual torna as mulheres vítimas e denigre sua imagem;

- Culto ao corpo feminino: referem-se à beleza do corpo feminino e sua exposição; várias expressões de baixo calão foram utilizadas para ressaltar a perfeição do corpo da modelo e das mulheres em geral;

- Comentários sarcásticos: piadas e deboches ao movimento e de apoio à campanha; a palavra "opressor" foi muito utilizada para isso; 
- Comentários agressivos: apareceram, principalmente, em diálogos, durante o conflito entre posicionamentos diferentes e quando as pessoas se referiram pejorativamente às feministas;

- Reforço de estereótipos sobre feministas: características pejorativas relacionados à sexualidade das mulheres e à estética das feministas;

- Marketing negativo e positivo: atributo reforçado por pessoas que consideram ruim a estratégia de marketing da empresa, julgando-a agressiva, desrespeitosa e desenvolvida para ganhar visibilidade; já o marketing positivo foi considerado pelos que acreditam que o discurso assumido é bom para gerar visibilidade;

- Comentários preconceituosos: comentários pejorativos sobre a sexualidade de homens que defenderam 0 direito das mulheres;

- Reforço de padrões estéticos: comentários sobre como deve ser o corpo da mulher.

O levantamento dos atributos reconhecidos e reforçados pelos públicos nas duas campanhas é um indício sobre a responsabilidade da comunicação organizacional em transmitir informação e conhecimento para estabelecer diálogo com e entre eles. Essa função não é meramente para sustentar que as imagens das organizações sejam positivas no decorrer dos anos, mas também para garantir sua responsabilidade social, a qual, entre outras características, é fundamental para o reconhecimento de direitos, estímulo ao respeito, formação de valores para a construção de relações sociais baseadas na ética.

\section{CONSIDERAÇÕES FINAIS}

As novas tecnologias de informação e comunicação possibilitam, cada vez mais, um ambiente democrático e participativo. Diante disso, é possível olhar de forma mais ampla o conceito de comunicação comunitária, defendendo que o ambiente virtual organiza comunidades, com as quais as organizações precisam dialogar para atender e responder a demandas e interesses.

Parte-se da ideia de que as comunidades que se formam nas mídias sociais também são afetadas pela atuação das organizações nesse ambiente e, portanto, ao estabelecerem relacionamentos e disseminarem seus discursos, as organizações precisam ser responsáveis para incentivar comportamento ético entre os sujeitos e demonstrar o seu comportamento ético diante da sociedade. Essa demonstração sugere uma atuação preocupada com o bem-estar e o desenvolvimento social. Com base nessa lógica, a comunicação organizacional configura-se como um agente de transformação social ao influenciar, direta ou indiretamente, a opinião pública e, a partir disso, sensibilizar a sociedade e potencializar a reflexão sobre temas relacionados à cidadania e ao interesse público.

Atualmente, verifica-se que a atuação das organizações nas mídias sociais colabora para reforçar o vínculo delas com 0 público e, assim, legitimar seu discurso e sua atuação no mercado. Mas, ao refletir sobre essa atuação é preciso considerar a responsabilidade que as organizações possuem ao desenvolver uma comunicação que irá gerar interações entre os sujeitos.

Nesse sentido, quando são analisados os atributos reforçados pelos públicos que interagiram nas campanhas da Skol e da Alezzia, percebe-se que o posicionamento da primeira dissemina valores construtivos importantes para o convívio 
coletivo, enquanto a segunda gera embates entre os sujeitos. Esses embates não são problemáticos, considerando que pontos de vista contrários podem ser importantes para reflexões e construção de novos valores e atitudes. Porém, a grande questão é que o reforço de preconceitos em um discurso organizacional é capaz de construir representações agressivas para a relação entre as pessoas na vida off-line.

Ao compreender que organizações socialmente responsáveis atuam pela diminuição de impactos e garantem o direito das pessoas, reforçar preconceitos não é uma atitude ética e responsável. É possível refletir, portanto, que os discursos das organizações possuem uma função orientadora de comportamentos, pois, ao disseminarem valores éticos, possibilitam um ambiente de diálogo baseado no respeito e, possivelmente, constroem sentidos que refletem nas relações sociais.

A análise das duas campanhas e dos posicionamentos das organizações demonstram que a comunicação organizacional possui um importante papel social na orientação de seus públicos em diversas esferas da sociedade. E que, por meio da tecnologia, elas podem estimular um debate importante para os direitos das pessoas, o que está diretamente ligado com ser responsável socialmente ou não. Conclui-se, portanto, que a comunicação organizacional gera impacto para a sociedade, principalmente em cenários nos quais existam tensões ideológicas. Por isso, uma organização responsável e ética precisa estimular o diálogo, esclarecer importantes informações e incentivar os indivíduos a construírem uma sociedade baseada em valores éticos.

Nesse sentido, os discursos das organizações são mediadores desse processo por serem uma constante construção e reconstrução de significados sobre práticas sociais e devem abordar temas de interesse que permitam articulações entre as pessoas. No momento que as organizações adquirirem a ciência disso, será possível aproximar ainda mais a tendência de transformar a responsabilidade social das organizações na construção de capital social para avançar rumo a uma participação que busque a discussão de interesses coletivos e uma atuação organizacional voltada para eles.

\section{REFERÊNCIAS}

FERRARI, Maria Aparecida. Contexto global e latino-americano da comunicação e relações públicas. In: GRUNIG, James E.; FERRARI, Maria Aparecida; FRANÇA, Fábio. Relações públicas. teoria, contexto e relacionamentos. 2. ed. São Caetano do Sul, SP: Difusão, 2011.

FONSECA JÚNIOR, Wilson C. Análise de conteúdo. In: DUARTE, Jorge; BARROS, Antonio Teixeira de (Orgs.). Métodos e técnicas de pesquisa em comunicação. 2. ed. São Paulo: Atlas, 2006.

HENRIQUES, Márcio Simeone. Comunicação e estratégias de mobilização social. Belo Horizonte: Autêntica, 2009.

JENKINS, Henry; GREEN, Joshua; FORD, Sam. Cultura da conexão: criando valor e significado por meio da mídia propagável. São Paulo: Aleph, 2014.

LUVIZOTTO, Caroline Kraus; SERIDÓRIO, Daniele Ferreira. Movimentos sociais, ativismo e participação na sociedade da informação. In: LUVIZOTTO, Caroline Kraus; LOSNAKC, Célio José; ROTHBERG, Danilo (Orgs.). Mídia e sociedade em transformação. São Paulo: Cultura Acadêmica, 2016.

MARTINO, Luís Mauro Sá. Teoria das mídias digitais. linguagens, ambientes e redes. 2. ed. Petrópolis, RJ: Vozes, 2015. 
MATOS, Heloiza. Capital social e comunicação: interfaces e articulações. São Paulo: Summus, 2009.

OLIVEIRA, Ivone de Lourdes; PAULA, M. A. Interações na contemporaneidade e mudanças paradigmáticas: organização, comunicação e estratégias. Revista del Foro Iberoamericano sobre Estrategias de Comunicación, Buenos Aires, Facultad de Ciencias Sociales, UNLZ, a. V, n. 14, p. 31-51, 2010.

RECUERO, Raquel. Comunidades virtuais: uma abordagem teórica. In: V SEMINÁRIO INTERNACIONAL DE COMUNICAÇÃO, V, Porto Alegre, 2001. Anais... Porto Alegre: PUCRS, 2001. Disponível em: <http://pontomidia.com.br/raquel/teorica.pdf>. Acesso em: 22 mar. 2017.

Redes sociais na internet. Porto Alegre: Sulina, 2010.

RHEINGOLD, Howard. La comunidad virtual: una sociedad sin fronteras. Barcelona: Gedisa Editorial, 1996.

SMITH, Vivian P. B. Incorporação dos princípios da responsabilidade social. Site Ethos, 2013. Disponível em: <http://www3.ethos. org.br/cedoc/incorporacao-dos-principios-da-responsabilidade-social/\#.WMcDjfnyu03>. Acesso em: 09 fev. 2017.

SROUR, Robert Henry. Poder, cultura e ética nas organizações. 3. ed. Rio de Janeiro: Campus, 2012.

.Ética empresarial. 4. ed. Rio de Janeiro: Elsevier, 2013.

Texto recebido em 08.04.2017 e aprovado em 19.06.2017. 